\title{
TEST STUDY ON BASIC STATIC CHARACTERISTICS OF CABLE SUPPORTED BARREL VAULT STRUCTURE
}

\author{
Wentao Qiao ${ }^{1, *}$, Zhihua Chen ${ }^{2}$ and Mingshan Zhao ${ }^{3}$ \\ ${ }^{1}$ Lecturer, School of Civil Engineering, Shi Jiazhuang Tiedao University, China \\ ${ }^{2}$ Professor, School of Civil Engineering, TianJin University, China \\ ${ }^{3} \mathrm{PhD}$. Student, School of Civil and environmental Engineering, Nanyang Technological University, Singapore \\ "(Corresponding author: E-mail: tottyer@126.com)
}

Received: 21 November 2011; Revised: 12 March 2012; Accepted: 20 March 2012

\begin{abstract}
By combining single layer cylindrical latticed shell (SLCLS) and beam string structure, a new-style prestressed spatial structure cable supported barrel vault structure (CSBV) is formed. Taking a practical CSBV project as prototype, a scaled model with a scale of 1:15 is designed and fabricated, the static loading test is carried out. Research results indicate that the characteristics of the prototype structure can be reflected by this model test. As the load increases, the change rule of the test values of the cables' forces agree with that of theoretical values. The two outmost cables' forces are generally smaller than the other interior cables' forces. The cables' forces in the symmetrical places keep closer. For rods' forces and nodal displacements of CSBV, the test values and theoretical values both keep closer. The differences between test values and theoretical values increases with the load. The test values are larger than the theoretical values, but the change rule still matches. Compared with SLCLS in the same condition, the rods' forces and nodal displacements of the CSBV are both smaller, and the mechanic characteristics of CSBV are more efficient.
\end{abstract}

Keywords: Cable supported barrel vault, Beam string structure, Cylindrical latticed shell, Rise-span ratio, Sag-span ratio, Strut number

\section{INTRODUCTION}

Spatial structures with longer span have gained more popularity in recent years. New types of spatial structures appear from time to time nowadays, such as cable dome structure, beam string structure, suspend-dome structure and cable supported barrel vault structure (CSBV). CSBV is a new-style highly efficient pre-stressed spatial structure. Inspired by beam string structure [1-7], and based on the single layer cylindrical latticed shell (SLCLS) [8], CSBV was first proposed. It consists of struts and cables distributed at suitable positions in the single layer cylindrical latticed shell. On one hand, stiffness of the whole structure is enhanced due to the introduction of pre-stressed cables and struts, which can effectively solve the problem SLCLS out-plane stability [9]. On the other hand, both steel usage and construction difficulty are significantly reduced. Moreover, horizontal forces that the supports bear and the burden on the lower structure are significantly reduced, due to the setting of cables which could be pre-stressed. This new-style structure was first proposed and its basic mechanical properties were theoretically studied in paper [10]. Theoretical research on mechanic feature of CSBV was carried out in paper [11], the initial prestress design method was proposed. The dynamic feature of CSBV was studied in papers [12] and [13], the wind resistant design method and seismic design method were respectively proposed.

Model test is one of the best methods to study mechanic feature of a new-style structure system. Directed by theoretical research results, the static loading test on a CSBV is carried out in this paper, and test details are listed below. 
First, SLCLS is tested under the whole span loading. Important variables including crucial members' strain values, horizontal displacements at supports and vertical displacements of crucial nodes at mid-span are monitored.

Second, CSBV with prestressed cables is tested under the whole span loading and important variables checked in the first step are monitored again.

By combing and comparing the results from the monitored two steps above, basic mechanical properties of CSBV are therefore concluded.

\section{EXPERIMENTAL MODEL AND LOADING SCHEME}

\subsection{Scaled Model}

Taking a practical CSBV project of a spinning mill as prototype, a scaled model with a scale of $1: 15$ is designed and fabricated. The span, length, rise and sag of the prototype are $50 \mathrm{~m}, 53.8 \mathrm{~m}$, $4.3 \mathrm{~m}$ and $0.7 \mathrm{~m}$ respectively. 7 cables are evenly spaced in the longitudinal direction, with 3 rods uniformly spaced in the span direction between each cable and the upper shell. The roof model is shown in Figure 1.

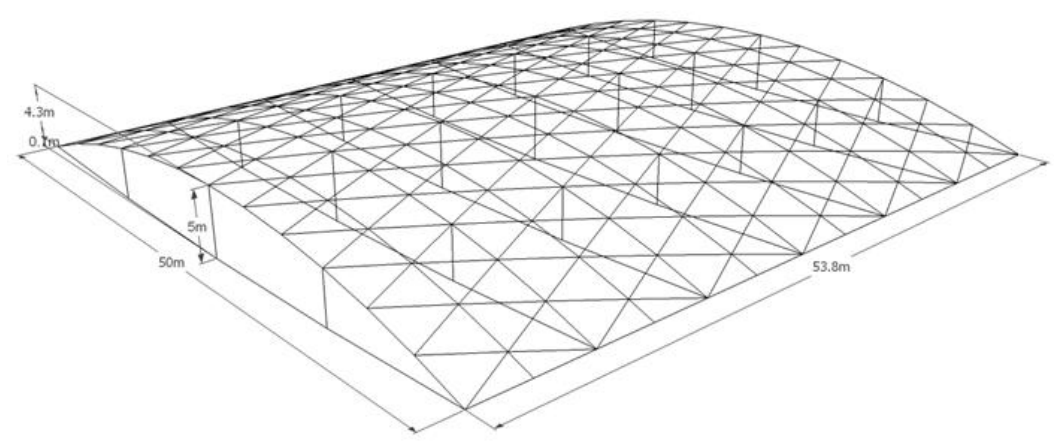

Figure 1. Cable Supported Barrel Vault Roof

The experimental model applies a 1:15 scale to the prototype, and the geometrical dimensions are calculated from the prototype according to the similarity constant and similarity ratio relationship in static loading experiment of engineering structure [14]. This scaled model has a $3.333 \mathrm{~m}$ span, $3.587 \mathrm{~m}$ length, $0.287 \mathrm{~m}$ rise and $0.047 \mathrm{~m}$ sag. Cross-sections of structural members are supposed to be chosen according to similarity ratio as well. Considering market supply and the requirement from welding, Q235B steel circular hollow sections with dimensions of $8 \mathrm{~mm} \times 1 \mathrm{~mm}, 10 \mathrm{~mm} \times$ $1 \mathrm{~mm}$ and $12 \mathrm{~mm} \times 1 \mathrm{~mm}$ are chosen. High strength steel wires with diameter of $6 \mathrm{~mm}$ and tensile strength of 600MPa are chosen as cables. The scaled model for test is shown in Figure 2. 


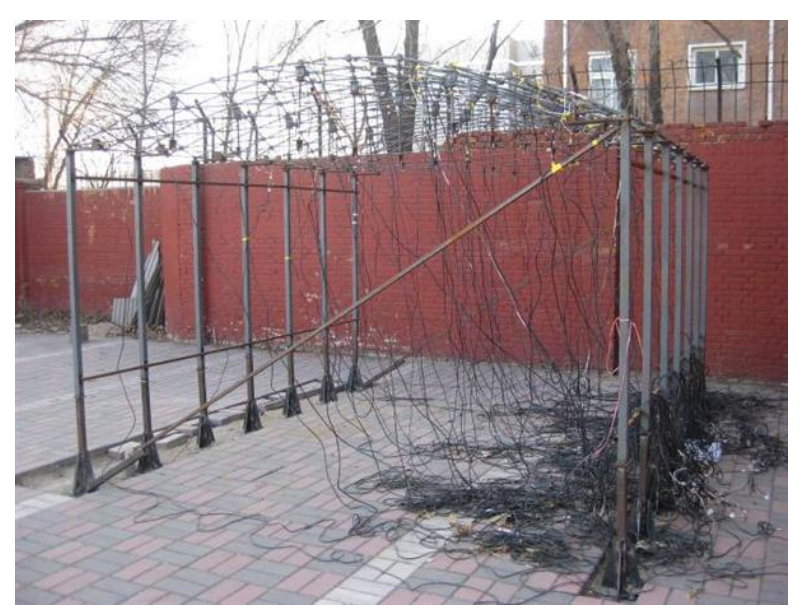

Figure 2. Scaled Model for Test

\section{$2.2 \quad$ Loading Scheme}

Considering the practical condition of the experimental model, hanging sand bags is chosen as loads, while the pre-stress in the cable is put by tightening the screw at the end of the cable, and the pre-stress value is measured by the strain of the steel bar at the end of the cable.

(1) Equivalent nodal loads

According to the actual load of the prototype and similarity ratio (ratio of surface load is 1:1), experimental loads are converted from the actual loads of prototype, which is calculated with the load condition as $1.2 \times$ dead load $+1.4 \times$ live load. Therefore the experimental load on the whole roof is designed to be $1.2 \times 0.8 \mathrm{kN} / \mathrm{m}^{2}+1.4 \times 0.5 \mathrm{kN} / \mathrm{m}^{2}=1.66 \mathrm{kN} / \mathrm{m}^{2}$. Since this barrel vault is relatively flat and the grids were uniformly distributed, the equivalent nodal loads are calculated according to the ratio of the horizontal projection area of each grid to that of the whole roof. Moreover, because the nodes sustained the roof surface load uniformly, the load each node bears is $15 \mathrm{Kg}$.

(2) Pre-stresses in cables

Pre-stresses in cables are considered to be concentrated loads which are 1/255 of the loads in cables of the prototype (similarity ratio is square of length similarity ratio). Therefore, the pre-stresses in cables are designed to be $75 \mathrm{~N}$ in the two outmost cables, and $85 \mathrm{~N}$ in the five middle cables. In this test, the tension prestress is put by tightening screws at the ends of cables, and the values are controlled by monitoring the strain of the steel bars at the end of the cables, i.e. Pre $=E \cdot \varepsilon \cdot A$ (Pre is the cable pre-stress, $E$ is the Young' s modulus of the steel bar, $\varepsilon$ is the strain, while $A$ is the area of the cross section of the steel bar.)

(3) Loading positions

Hanging method is employed to put the equivalent nodal forces, and there are 149 nodes in total responsible for equivalent node forces. However, only 30 nodes are chosen as the loading positions by taking the advantage of structural symmetry, and the goals of the test is not affected in this case. The loading positions are shown in Figure 3, in which the points covered by dash lines are not loaded during half span test. 


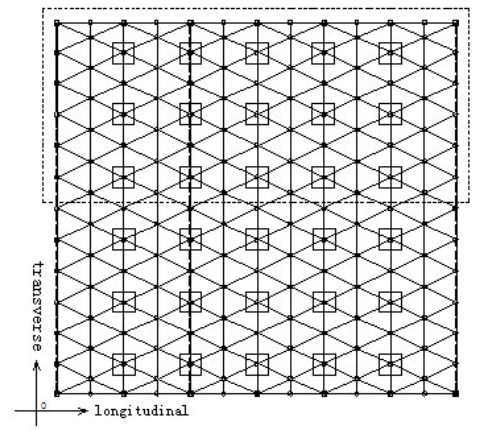

Figure 3. Locations for Loading

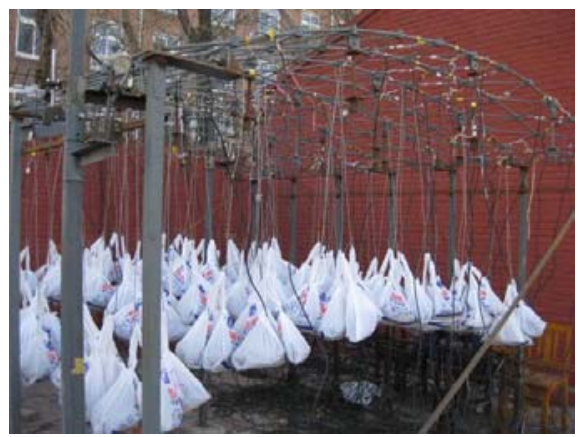

Figure 4. Full-span Load

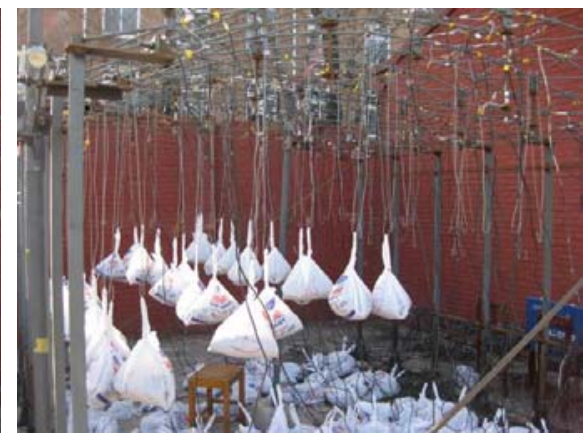

Figure 5. Half-span Load

\section{$2.3 \quad$ Loading Steps}

Considering that the bearing capacity of the SLCLS experimental model is low, the load each node has to carry in SLCLS test is set as only 3Kg, i.e. $20 \%$ of that in CSBV test, and both loading and unloading procedures are divided into 2 steps (50\% load for each step). For CSBV test, the load for each node to carry at full loading is $15 \mathrm{Kg}$, and it is divided into 6 steps. The detailed loading scheme is shown in Table 1.

Table 1. Load Step Increments

\begin{tabular}{|c|c|c|c|}
\hline No. & $\begin{array}{c}\text { Ratio } \\
(\%)\end{array}$ & $\begin{array}{c}\text { Load } \\
(\mathrm{kg})\end{array}$ & $\begin{array}{c}\text { Increment } \\
(\mathrm{kg})\end{array}$ \\
\hline 1 & 20 & 3 & 0 \\
\hline 2 & 50 & 7.5 & 4.5 \\
\hline 3 & 70 & 10.5 & 3 \\
\hline 4 & 80 & 12 & 1.5 \\
\hline 5 & 90 & 13.5 & 1.5 \\
\hline 6 & 100 & 15 & 1.5 \\
\hline
\end{tabular}

\section{DATA MEASUREMENT AND RECORD}

\subsection{Equipments For Measurement}

Two sets of 60 points YE2539 high speed static strain indicator, and one computer are employed as the strain measurement system, while the structure displacements are measured by dial indicators, as shown in Figure 6 and Figure 7.

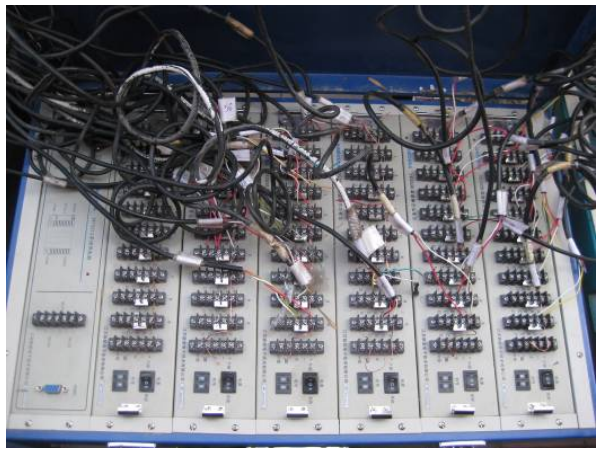

Figure 6. High-speed Static Strain Indicator

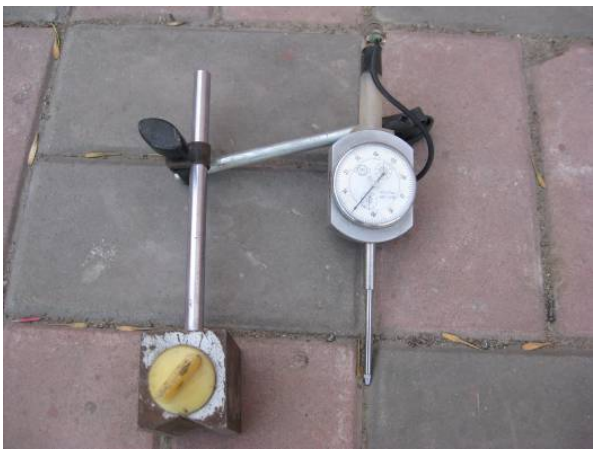

Figure 7. Dial Indicator 


\subsection{Measured points}

Before the experiment, the structural members with large stress (stress ratio exceeds 0.6) and nodes with largest displacements are found and marked by theoretical analysis in Midas/gen. Strain of those structural members and displacements of those nodes are monitored during the test as the crucial indicators for evaluating the whole structure system. The single cylindrical latticed shell part of CSBV consists of rod pieces with 3 different cross section areas. Different marks were employed to differentiate each type of rod piece.

As shown in Figure 8, the measured strain points are numbered from up to down in the transverse direction and then from left to right in the longitudinal direction. The points on rods are marked from No. 1 to 73, and the points on struts are marked from No. 74 to 82, while the points on steel bar at the end of the cables are marked from No. 83 to 96.

Besides, vertical displacements at mid-span are monitored at the position marked No. 1 and 2, while horizontal displacements at supports are measured by dial indicator at positions marked from No. 3 to 6.

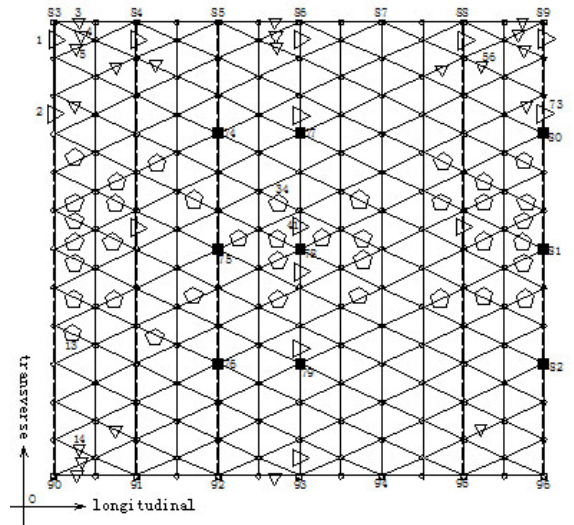

Figure 8. Nodes and No. for Strain Survey

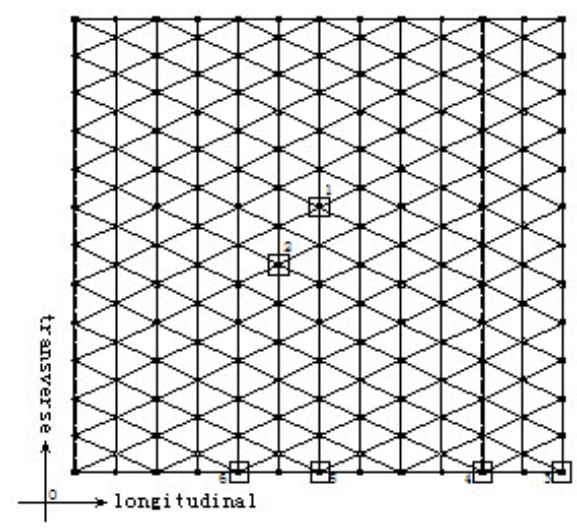

Figure 9. Nodes and No. for Displacement Survey

\subsection{Data Recording}

Data recording starts 5 minutes later after each loading step each data is recorded 6 times, with 2minute interval each time. Then, next loading increment is put 1 minute later after 6 times data collection. The unloading step and data recording procedure keep the same with the loading.

The time is set as 0 when the first loading step is finished, then the first data collection time is 5 , and the second is $7, \cdots$, the second loading step happens at time 16 , and so on. For measurement of displacements, data is recorded after all the strain data are recorded but before next loading step. The detailed schedule for loading and recording is shown in Table 2.

Considering that the whole structure needs some time to finish internal force re-distribution, data recoded at time closer to ideal equilibrium status takes up more weight in calculating the final strain by weighted average method. Supposing the whole weight being $P=1+2+3+\cdots+n$, then the first data weight is $1 / P$, and the $n^{\text {th }}$ data weight is $n / P$. As a result, the formula calculating the final strain and stress can be written as below. 
Table 2. Time for Loading and Recording Data (min)

\begin{tabular}{|c|c|c|c|c|c|c|c|}
\hline $\begin{array}{c}\text { No. of } \\
\text { load step }\end{array}$ & $\begin{array}{c}\text { Loading } \\
\text { time }\end{array}$ & $\begin{array}{c}1^{\text {st }} \\
\text { recording } \\
\text { time }\end{array}$ & $\begin{array}{c}2^{\text {nd }} \\
\text { recording } \\
\text { time }\end{array}$ & $\begin{array}{c}3^{\text {rd }} \\
\text { recording } \\
\text { time }\end{array}$ & $\begin{array}{c}4^{\text {th }} \\
\text { recording } \\
\text { time }\end{array}$ & $\begin{array}{c}5^{\text {th }} \\
\text { recording } \\
\text { time }\end{array}$ & $\begin{array}{c}6^{\text {th }} \\
\text { recording } \\
\text { time }\end{array}$ \\
\hline 1 & 0 & 5 & 7 & 9 & 11 & 13 & 15 \\
\hline 2 & 16 & 21 & 23 & 25 & 27 & 29 & 31 \\
\hline 4 & 32 & 37 & 39 & 41 & 43 & 45 & 47 \\
\hline 5 & 48 & 53 & 55 & 57 & 59 & 61 & 63 \\
\hline 6 & 84 & 69 & 71 & 73 & 75 & 77 & 79 \\
\hline
\end{tabular}

$\varepsilon=\sum_{i=n}^{P} \varepsilon_{i} \cdot(i-n) /(1+2+\ldots+n)$

$\sigma=\varepsilon \cdot E$

$E=2.06 \times 10^{11} \mathrm{~N} / \mathrm{m}^{2}$

Where, $E$ is the Young' $\mathrm{s}$ modulus of the steel, $\varepsilon$ is the strain, $\varepsilon_{i}$ is the strain of $i^{\text {th }}, \sigma$ is the stress.

In this test, data at each loading step is recorded 6 times, among which at last 3 times are considered to be stable enough and effective. Therefore, they are chosen to calculate the final strain and stress, and $n$ equals to 3 in this case.

\section{EXPERIMENTAL RESULTS ANALYSIS}

The numerical analysis of the experimental model has been carried out by Midas/gen. In the numerical model, beam element is employed to simulate the rods, columns and connection beams; truss element is employed to simulate the struts and braces; cable element is employed to simulate the cables. The characteristics of these elements are introduced detailedly in the manual of Midas/gen. Results from the theoretical analysis are compared with the test in the next section.

\subsection{Stresses In Members Of SLCLS}

(1) Strain-time relationship

It can be founded that the strain-time relationship of each load step almost keeps same by analysing all the strain data collected in the test. Take CSBV as an example, under the whole span loading, the strain-time relationship of the measured point No. 2(A1) and No. 41(A2) are shown in Figure 10. 


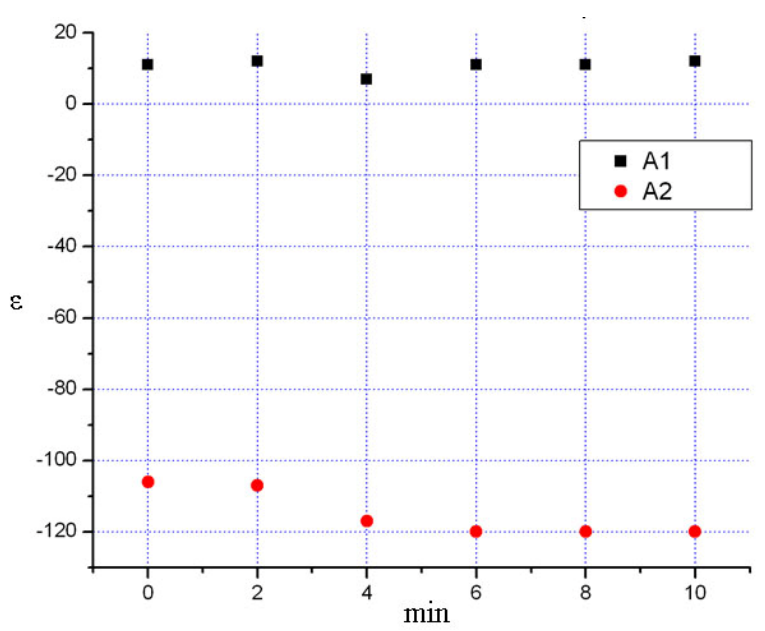

Figure 10. Strain-time Relation Curve

Therefore, the final strain of the measured members can be calculated by filling the data recorded at last 3 times into the formula provided in 3.3. 6 representative rods are analysed in detail in this paper, which are marked as A1, A2, B1, B2, C1, and C2 (corresponding number is 2, 41, 13, 34, 4, and 56 in Figure 8).

(2) Comparison study of stress in members

To study the stress variation rules, stresses of crucial members in CSBV are compared with those in SLCLS, as shown in Figure 11. In addition, stresses of the members from the experimental model are amplified by similarity ratio in order to approximately simulate the stresses in the prototype structure. Then, the results are compared with the theoretical analysis of the prototype structure. The comparison for CSBV is shown in Figure 12.

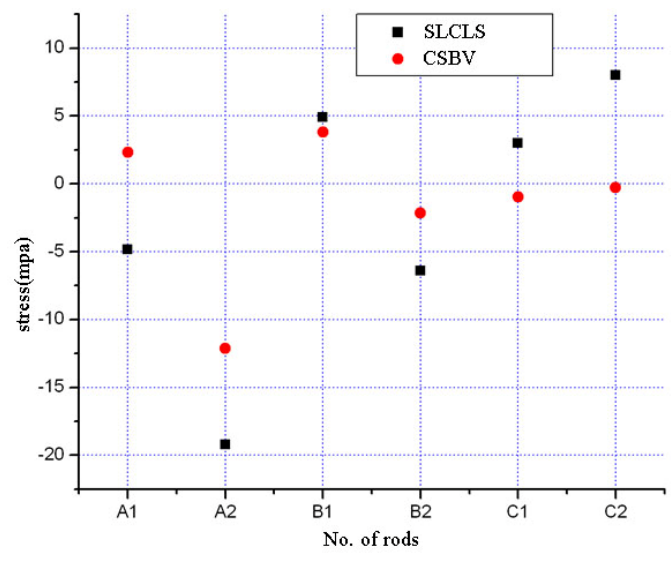

Figure 11. Force Contrast between Different Structures

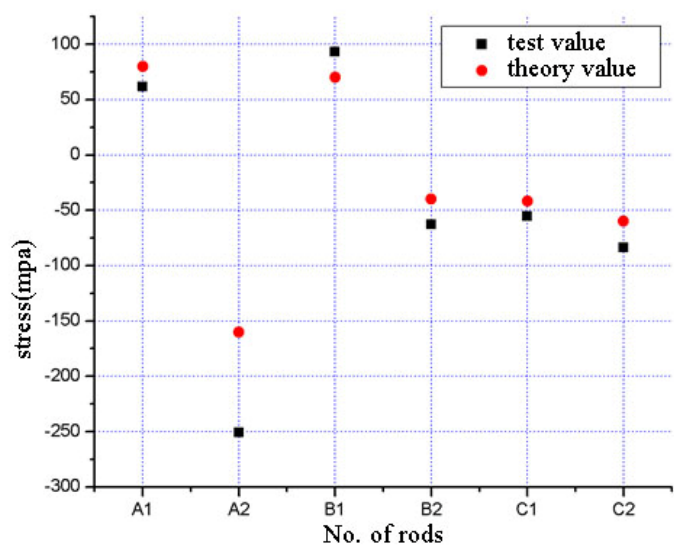

Figure 12. Force Contrast between Scaled Model and Prototype

By comparing the stresses of members of SLCLS and CSBV at the same loading level, it is found from the Figure 11 that the rods stresses of SLCLS are all bigger than that of CSBV, and the biggest member stress of SLCLS reaches 20MPa, while that of CSBV is only $12 \mathrm{MPa}$ in the same condition. The stress level of rods in CSBV is about $60 \%$ of SLCLS, CSBV is more efficient in transmission internal force than SLCLS. It can be seen from Figure 12 that the biggest calculated stress in prototype is $250.8 \mathrm{MPa}$, while the numerical modeling counterpart is $180 \mathrm{MPa}$. In this case, the difference between these two values is about $36 \%$. The difference between the two values in other members is smaller, ranging from $20 \%$ to $30 \%$. In a word, the difference level is relatively high, and the experimental values are larger than numerical analysis values. The difference may come 
from the choosing of members by approximate similarity ratio, imperfection of model machining, simplification of boundary conditions in experiment model and data measurement. However, the difference won't influence the goal of the test. The mechanical properties of the prototype structure under practical loading condition can be reflected through this model test.

(3) Member stress in CSBV

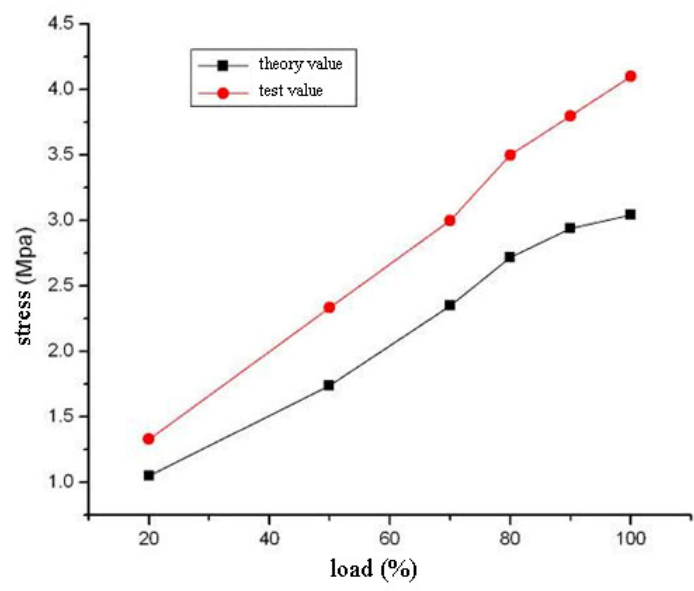

Figure 13. Rod A1 Stress

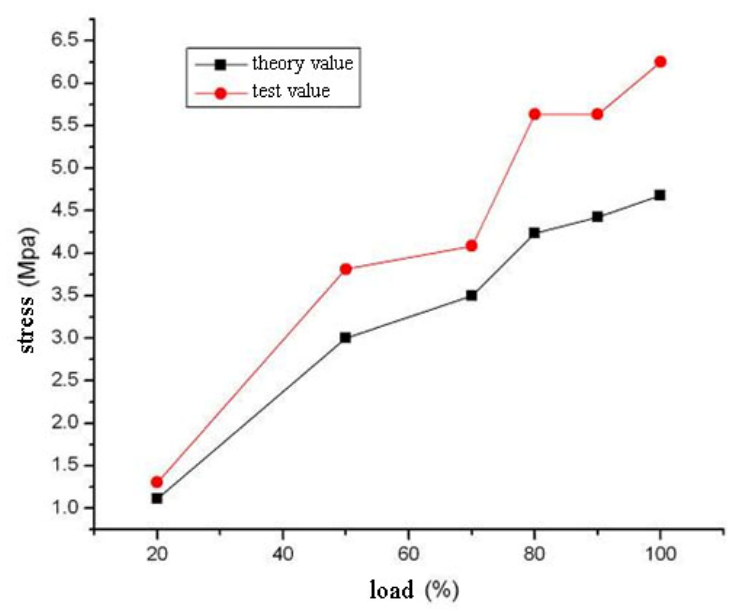

Figure 15. Rod B1 Stress

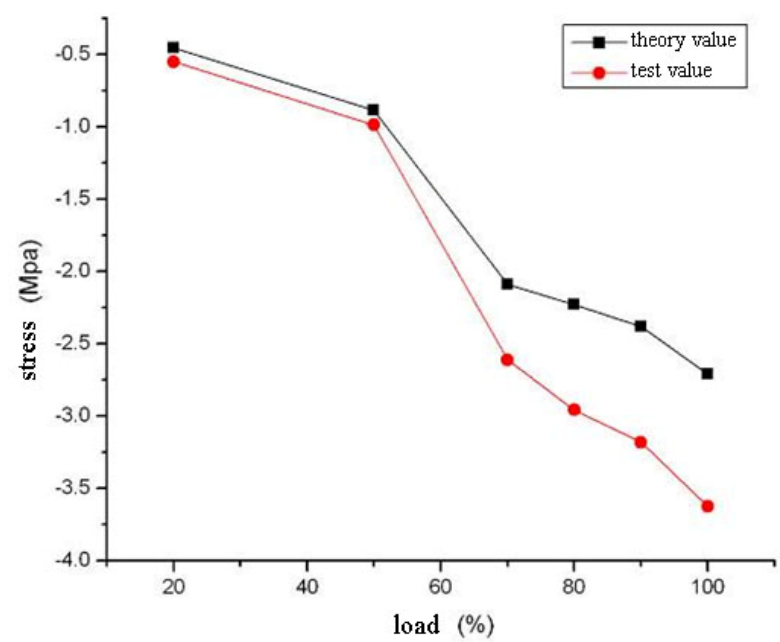

Figure 17. Rod C1 Stress

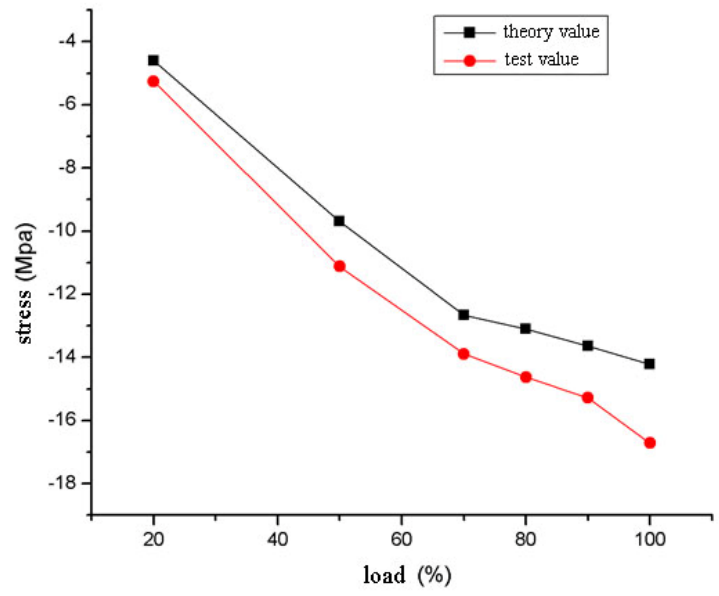

Figure 14. Rod A2 Stress

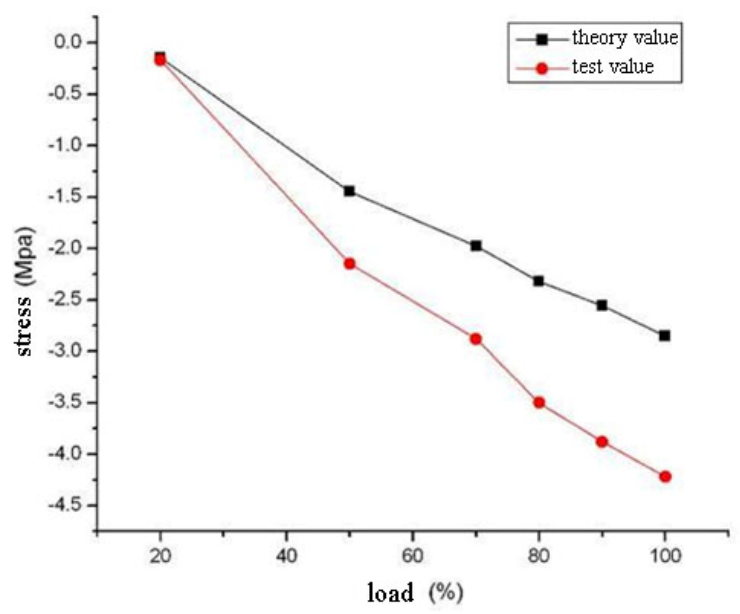

Figure 16. Rod B2 Stress

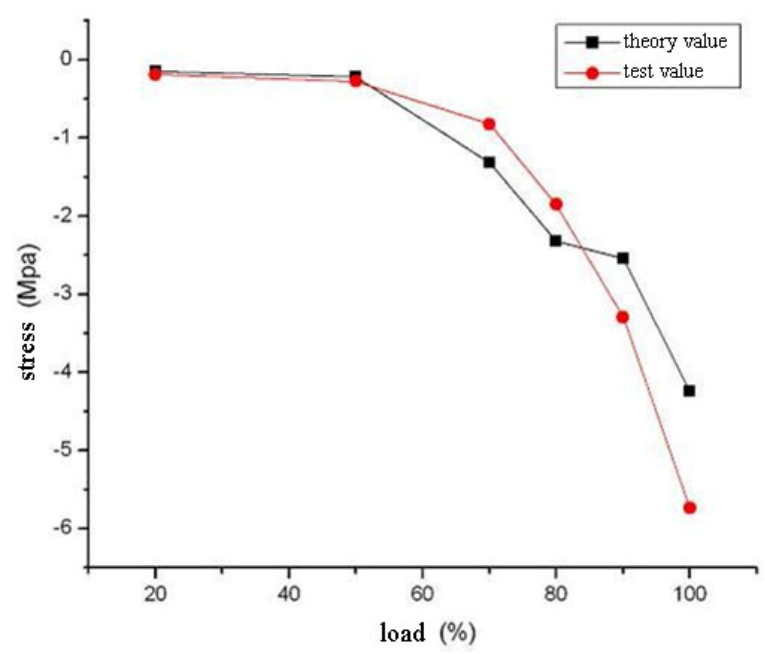

Figure 18. Rod C2 Stress 
The stress-load curves of members are drawn in Figure 13 to Figure 18. It can be obviously seen that the variation of experimental results and numerical analysis results are nearly the same. Essentially, both of them increase with the increase of load, and the experimental values are generally larger than those of the numerical analysis. However, the difference between these two is small at the beginning, and increases with the increase of load. In addition, for both experimental and numerical analysis results, most members' stress-load curves tend to deviate from the straight line in different extents, which reveals that for CSBV, stress-load relationship of rods in the single layer lattice shell tend to be non-linear.

\subsection{Stresses In Cables}

Cables in CSBV, whose inner forces directly affect the mechanical properties of the whole structure, are the kernel of CSBV. In order to precisely control the pre-stress of the cables during the test, the method of tightening the screw at the end of cable and real-time monitoring to the strain of the cable are employed. All the 7 cables are installed on the experimental model, the measured points on the cables and the associated numbers are shown in Figure 8, where points No. 83-89 are chosen as the main study objects, the corresponding number is No. 1 to No. 7 in Figure 19 and Figure 21.

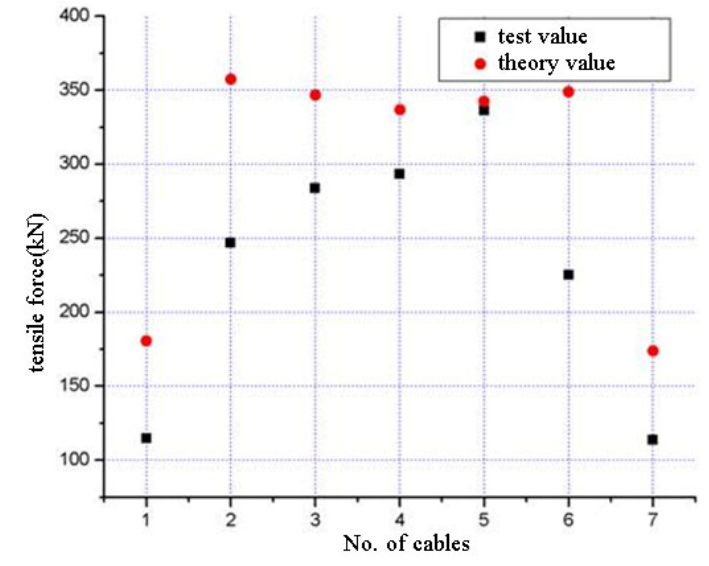

Figure 19. Cable Forces Contrast between Scaled Model and Prototype

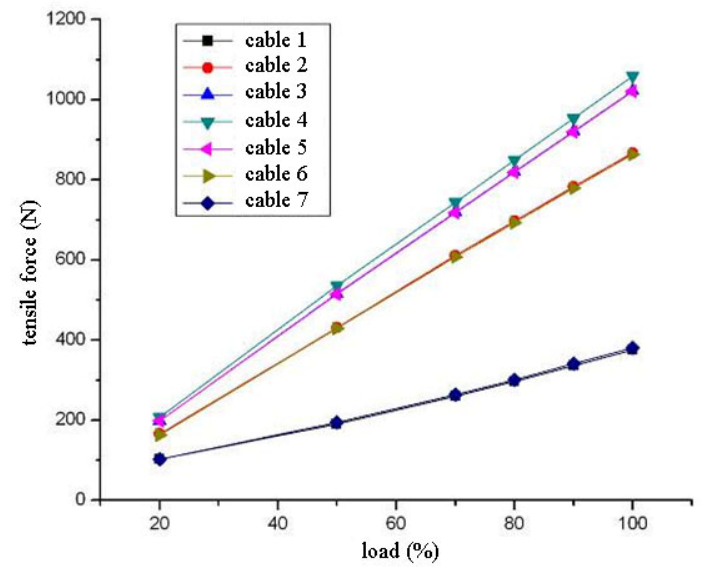

Figure 20. Theoretical Value of Cables' Forces

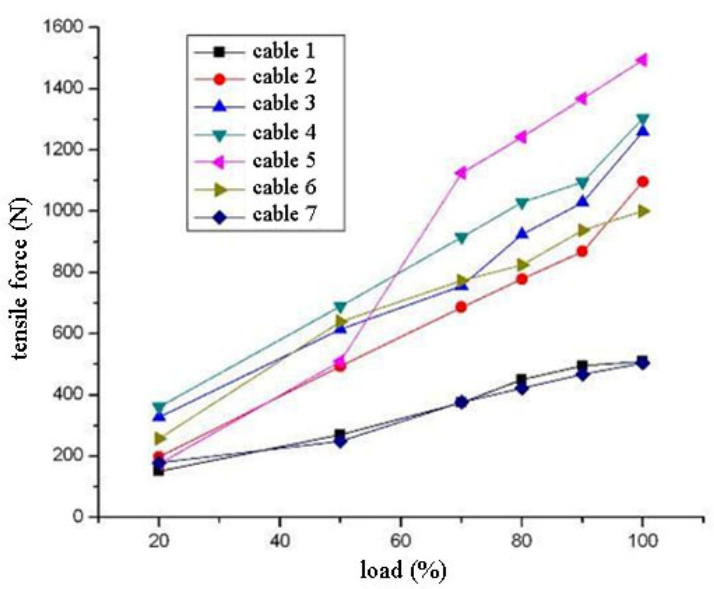

Figure 21. Test Value of Cables' Forces

As shown in Figure 19, the experimental regression value of cable 1 under full loading to the prototype is $114.75 \mathrm{kN}$, while the numerical analysis result of that is $180.5 \mathrm{kN}$, the difference between which is about $60 \%$. Although this difference in other cables is smaller, the general error level is high and experimental values are always smaller than numerical analysis values. 
Moreover, in Figure 20, the numerical analysis results of stresses in each cable vary linearly with loading, and cables in symmetrical positions have the same stress values. In Figure 21, the experimental results variation also shows approximate linearity, but stresses in symmetrical positions do not show strict symmetry. Especially for cable 5 whose stress varies oddly. However, the variation rule of these two types of results is basically the same although the difference does exist to a certain extent.

\subsection{Nodal Displacements}

As it is known that SLCLS has poor out-plane stability and supports suffer from large horizontal force as well. By installing cables and vertical struts, SLCLS can be transformed into CSBV which results in better out-plane stability, while the problem of horizontal force to the supports is also solved. The horizontal displacements at supports and vertical displacements at the mid-span are the indicators of how well the structure can handle these two problems. Therefore, the displacement indicators are assigned and located at mid-span nodes and supports to measure the biggest vertical displacement at mid-span (No. 1 and 2), and the horizontal displacement at supports (No. 3 to 6). Locations and number are shown in Figure 9.

(1) Comparison study of crucial nodal displacements

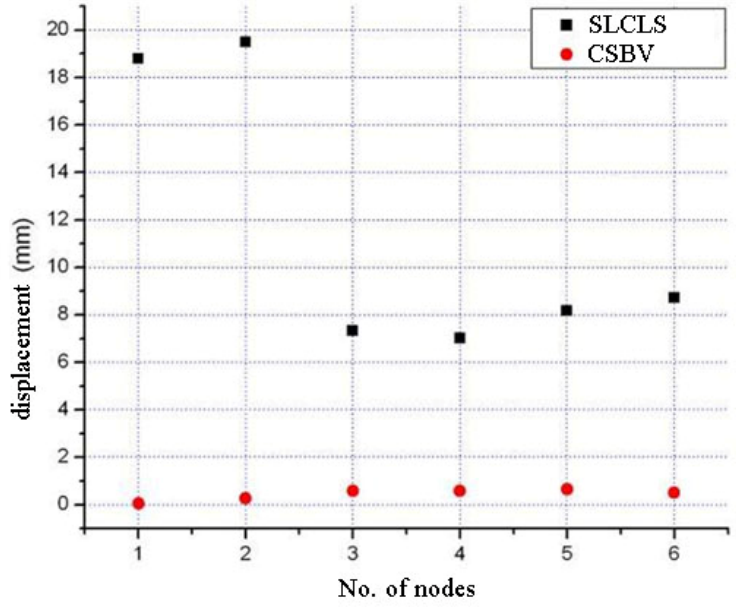

Figure 22. Displacement Contrast between Different Structures

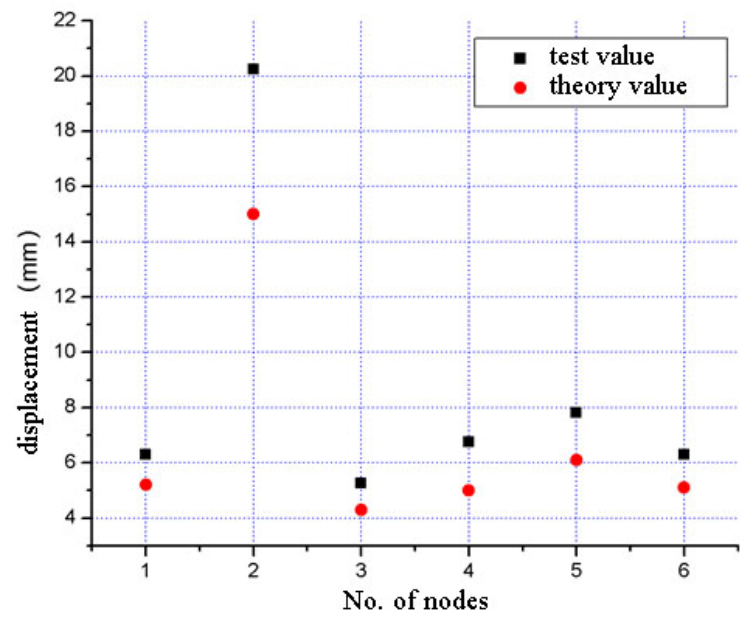

Figure 23. Displacement Contrast between Scaled Model and Prototype

As shown in Figure 22, when the SLCLS is imposed 20\% of the designed load, the biggest vertical nodal displacement reaches $19 \mathrm{~mm}$ and the biggest horizontal displacement at supports is $9 \mathrm{~mm}$, while those in CSBV are only $0.2 \mathrm{~mm}$ and $0.5 \mathrm{~mm}$, respectively, at the same load level. As for the aspect of structure deformation, it also can be revealed that CSBV behaves much better than SLCLS in mechanic characteristics. In Figure 23, the experimental regression value of vertical displacement is $20.25 \mathrm{~mm}$, while the numerical analysis gives $15 \mathrm{~mm}$. That is, experimental values are always larger than those of numerical analysis. The difference between these two values is about 35\%. For the other nodal displacements, most of them are smaller but still above $20 \%$. 
(2) Nodal displacements in CSBV

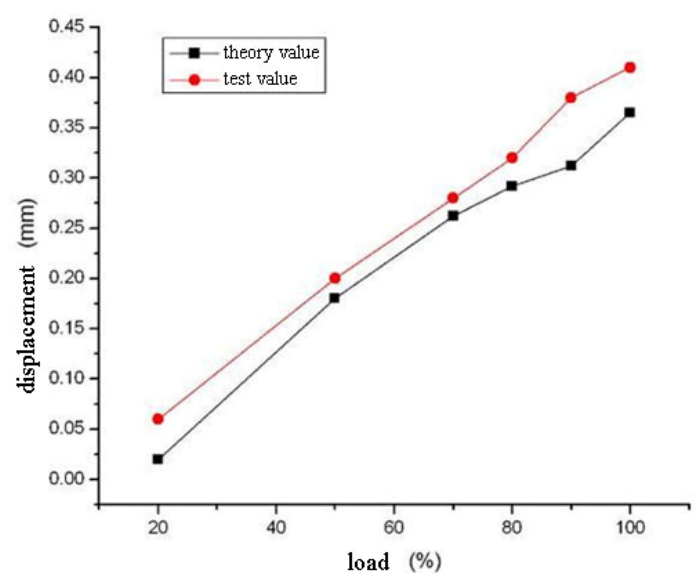

Figure 24. Node 1 Vertical Displacement

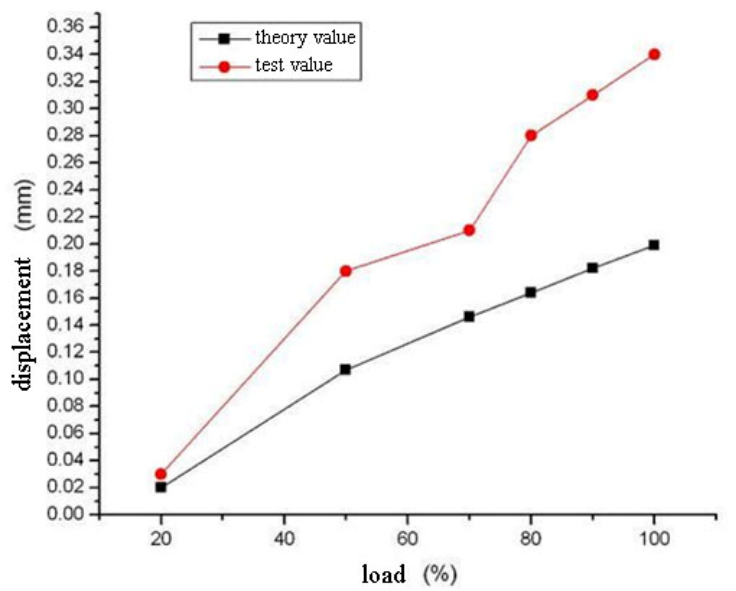

Figure 26. Node 3 Lateral Displacement

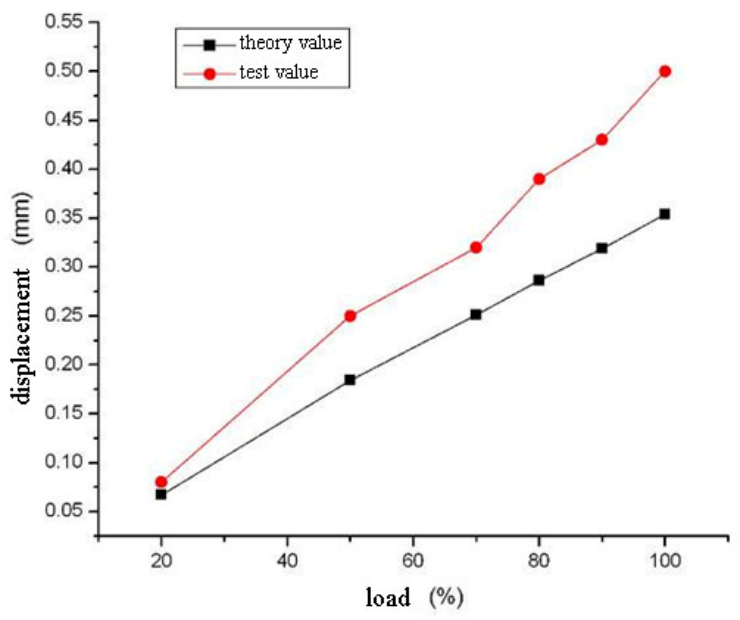

Figure 28. Node 5 Lateral Displacement

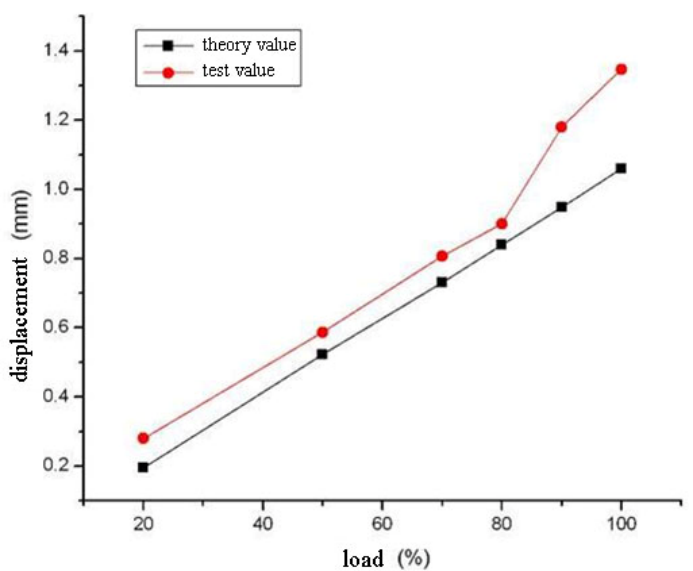

Figure 25. Node 2 Vertical Displacement

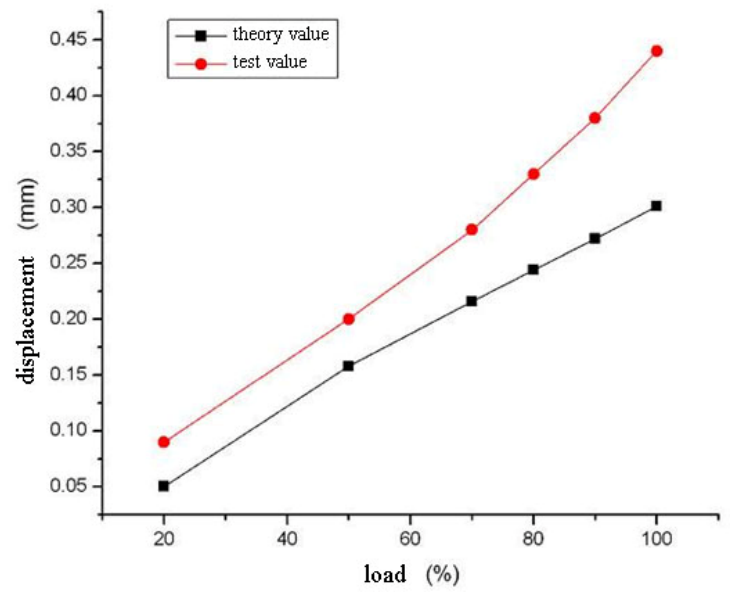

Figure 27. Node 4 Lateral Displacement

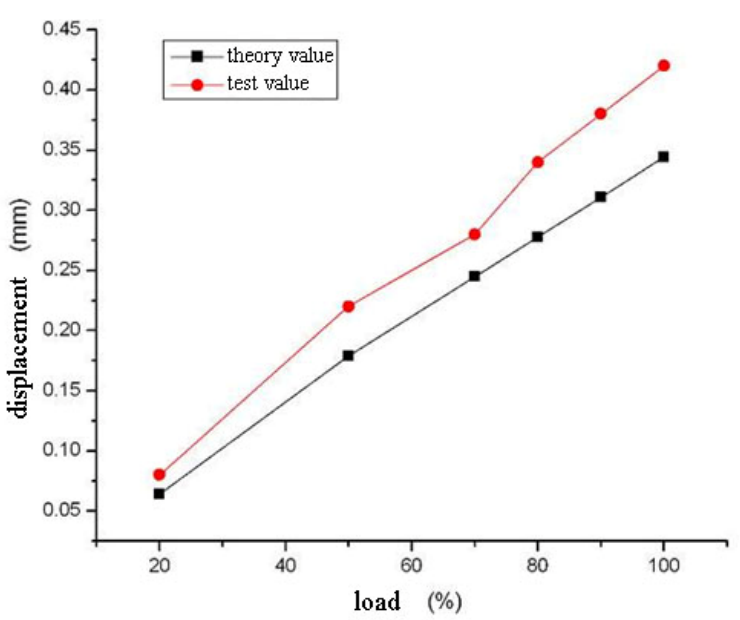

Figure 29. Node 6 Lateral Displacement

From Figure 24 and Figure 25, it can be easily seen that the vertical displacements of node 1 and 2 are generally changing linearly with loading although fluctuation exist in some special conditions. Additionally, experimental results are very close to numerical analysis, and they basically shared the same variation rule. Experimental results are always larger than numerical results and difference is small at the beginning but grows with loading. In Figure 26 to Figure 29, the same displacement-load relationship is demonstrated for horizontal displacements at supports. 


\section{CONCLUSIONS}

Based on the existing theoretical research, we have designed and fabricated a 1:15 (specimen to prototype) scaled model, and have carried out a series of static loading tests on this experimental model. The research results have shown that this experimental model can reflect the basic mechanic properties of the prototype structure, the following conclusions have been drawn.

(1) Rods' stresses in CSBV obtained via experiments and numerical analysis keep close at the beginning but deviate with loading. Although the difference between these two types of results increase with loading, the stress-load relationship still holds.

(2) Stresses in cables obtained in experiments and numerical analysis show approximately the same stress-load relationship. Generally speaking, stresses in cables at the ends are smaller than that at inner positions. Stresses in cables at symmetrical positions are very close due to symmetry.

(3) Nodal displacements in experiments and numerical analysis show similar displacement-load relationship. They are close to each other, but experimental results are larger. Although these two types of results differ more as the loading increases, the displacement-load relationship still holds.

(4) To sum up, by setting struts and cables at suitable positions on SLCLS, the formed CSBV has much better rigidity, out-plane stability and the significantly reduced horizontal forces at supports. CSBV is a new-style and highly efficient spatial structure with larger span and needing less steel.

\section{REFERENCES}

[1] Masao, S. and Kurasiro, T., "A Study on Structural Behaviors of Beam String Structure”, Summaries of Technical Papers of Annual Meeting Architectural Institute of Japan [C], Tokyo, Japan, B 1.1985, pp. 280-284.

[2] Masao, S. and Kurasiro, T., "A Study on Structural Behaviors of Beam String Structure”, Summaries of Technical Papers of Annual Meeting Architectural Institute of Japan [C], Tokyo, Japan, B 1.1985, pp. 280-284.

[3] Masao, S., “A Study on Structural Planning of Radial Type Beam String Structures", Summaries of Technical Papers of Annual Meeting Architectural Institute of Japan [C], Tokyo, Japan, B 1.1988, pp. 1365-1366.

[4] Masao, S. and Ohtake, T., "A Study on Beam String Structure with Flat Circular Arch”, Summaries of Technical Papers of Annual Meeting Architectural Institute of Japan [C], Tokyo, Japan, B 1.1988, pp. 1369-1374.

[5] Masao, S. and Okasa, A., "The Role of String in Hybrid String Structure", Engineering Structures, 1999, Vol. 21, No. 8, pp. 756-69.

[6] Wu, M.E., "Analytical Method for the Lateral Buckling of the Struts in Beam String Structures”, Engineering Structures, 2008, Vol. 30, No. 9, pp. 2301-2310.

[7] Xue, W.C. and Liu, S., "Design Optimization and Experimental Study on Beam String Structures”, Journal of Constructional Steel Research, 2008, No. 9, pp. 1-11.

[8] Shen, Z.Y. and Chen, Y.J., "Spatial Truss and Latticed Shell”, Shanghai : Tongji University Press, 1997. [in Chinese]

[9] Shen, S.Z. and Chen, X., "Stability of the Shell Structures”, Beijing: Science Press, 1999. [in Chinese]

[10] Chen, Z.H., Qiao, W.T. and Yang, X.Y., “Cable Supported Barrel Vault Structure System and Research on Mechanics Characteristics”, International Journal of Advanced Steel Construction, 2010, Vol. 6, No. 3, pp. 867-878. 
[11] Chen, Z.H. and Qiao, W.T., "Prestress Design and Stability Research of Cable Supported Barrel Vault Structures”, Journal of Building Structures (Supplement), 2010, Vol. 31, pp. 227-233. [in Chinese]

[12] Qiao, W.T. and Chen, Z.H., “Analysis on Wind-induced Vibration Response of Cable Supported Barrel Vault Structures”, Building Structure, 2010, Vol. 40, No. 5, pp. 108-111. [in Chinese]

[13] Qiao, W.T. and Chen, Z.H., "Seismic Response Analysis of Cable Supported Barrel Vault Structures under Multi-support Excitations”, Spatial Structures, 2011, Vol. 1, pp. 15-20. [in Chinese]

[14] Li, Z.X., “Theory and Technique of Engineering Structure Experiments”, TianJin: Tianjin University Press, 2004. [in Chinese] 